\title{
A CONTRIBUTION TO RESEARCH OF THE INFLUENCE OF DEGRADATION OF VEHICLE VIBRATION PARAMETERS ON THERMAL LOAD OF SHOCK ABSORBERS
}

\author{
Dr Miroslav Demić* \\ University of Kragujevac, Faculty of Engineering Sciences, Kragujevac, Serbia \\ Dr Đorđe Diligenski \\ University of Belgrade, Vinča Institute of Nuclear Sciences, Dept. of IC Engines \\ and Vehicles, Belgrade, Serbia
}

Dr Milan Milovanović

Zastava Vehicles Group, Kragujevac, Serbia

Dynamic simulation, based on modelling, has a significant role during to the process of vehicle development. It is especially important in the first stages of vehicle design, when relevant parameters are to be defined. In practice, it is commonly assumed that vehicle vibration parameters are invariable, what is basically not true. Many investigations have shown that vibration parameters degrade in service conditions, what consquently leads to the variation of dynamic characteristics of a vehicle. This paper attempts to indicate, on the basis of the preliminary results, a need to introduce these variations, caused by the thermal impact, in the early stages of vehicle design through the adequate vehicle modelling.

Key words: Vehicle, Vibration parameters, Degradation, Vibration comfort, Thermal load of shock absorbers

\section{INTRODUCTION}

Shock absorbers are an integral part of the elastic suspension system, which directly affect the active vehicle safety. The role of damping in addition to the basic, is to absorb mechanical vibrations transferred from the ground and to ensure the safety of passengers in a vehicle.

As it is known, in shock absorbers the kinetic energy of the system transforms into mechanical work or heat [17, 18, $20,26-28]$. In practice, in the stage of vehicle development, shock absorber parameters are chosen from the condition of damping of vehicle vibrations, but in order to avoid the negative impact on the function, thermal loads should be taken into consideration [26, $28,30]$. The goal is to get as much mechanical work received from the ground into thermal energy to be transferred to the environment and thus provide the cooling of shock absorbers. Wrong choice of shock absorbers, from the standpoint of thermal loads, can cause a rapid degradation of its properties during service. Too much heat, eventually kept "inside" the shock absorber, would cause rapid deterioration of sealing elements and consequently the loss of function of the damping element.

Tests have shown that mechanical work is partly converted into heat which is transferred to the working fluid and shock absorbers body, and the remaining amount of heat delivery is transferred to the environment and thus cools the absorber. Mathematically, it can be displayed by the formula $[26,30]$ :

$$
A=Q_{t}+Q_{f}+Q_{o}
$$

where:

- A - mechanical work (equal to the quantity of heat),

- $Q_{t}$ - quantity of heat transferred to the shock absorbers body,

- $Q_{f}$ - quantity of heat transferred to the working fluid, and

- $Q_{o}$ - quantity of heat transferred to the environment. 
The work of the force in the shock absorber is interesting because of the analysis of its transformation into heat energy. The force work in the shock absorber is experimentally measurable, but it is hard to measure the amount of heat released from the absorber [26]. This phenomenon is complex and difficult to measure, because it is known that a part of the energy is spent to heat shock absorbers elements, such as piston, cylinder, working fluid, etc. In addition, the nature of heat transfer from the shock absorber to the environment is very complex. Heat transfer is carried out by convection, as dominant, and less by conduction and radiation $[26,28]$.

From the point of maximal cooling, proper selection of shock absorbers requires a comprehensive analysis of the transformation of mechanical energy into heat. Method of transformation of mechanical energy into heat is largely determined by the shock absorbers design. It is not possible to influence directly on the conduction of heat and radiation from the absorber. It is necessary to increase the influence of the heat transfer by convection from the absorber to the surrounding environment, as dominant appearance. This is best achieved by design of the vehicle body (fender). The idea is to utilize convection flow of the air around the absorber, with the least complexity of the structure. In practice, this solution is rarely used, but can certainly be applied. Making some kind of air deflectors on the elements of the body should increase the effect of convective heat transfer to the environment.

Note that the objective of this study was not to analyze the cooling of the shock absorber, but only thermal load to which it is exposed. Therefore, it was deemed expedient to analyze the heat which is obtained by converting mechanical work into heat energy per time unit. Mechanical work was calculated by use of mechanical model of the vehicle, which will be discussed below. In addition, it is known that in service condition, vehicle vibration parameters vary with vehicle aging [16], including shock absorbers, and therefore it was deemed appropriate to investigate whether and how much influence of degradation of shock absorber parameters does on its thermal load.

\section{VEHICLE MODEL}

As mentioned above, kinetic energy due to motion of shock absorber elements is transformed into mechanical work, which is further converted into thermal energy by the mutual friction of mov- ing elements of the shock absorber and oil flow through the corresponding holes is [28]. This process will, in this paper, be explained by use of vehicle vibration model.

\section{Vehicle vibration model}

The structure of the vehicle model is selected depending on values to be analyzed [7-13, 16$18,20,33]$. Consequently, in practice, vibration models using different structure and complexity are utilized. In fact, the choice of model should tend to a solution as simple as possible, but to enable simulation of the desired value $[7-13,16]$. Bearing in mind that the aim of this study was to emphasize a need to involve vibration parameters degradation in the model, which will allow the study of shock absorber heat loads, it was found useful to observe vehicle vibration model, which is often, in the literature, called the quarter model [7-13, 16-18, 20, 33], shown in Figure 1.

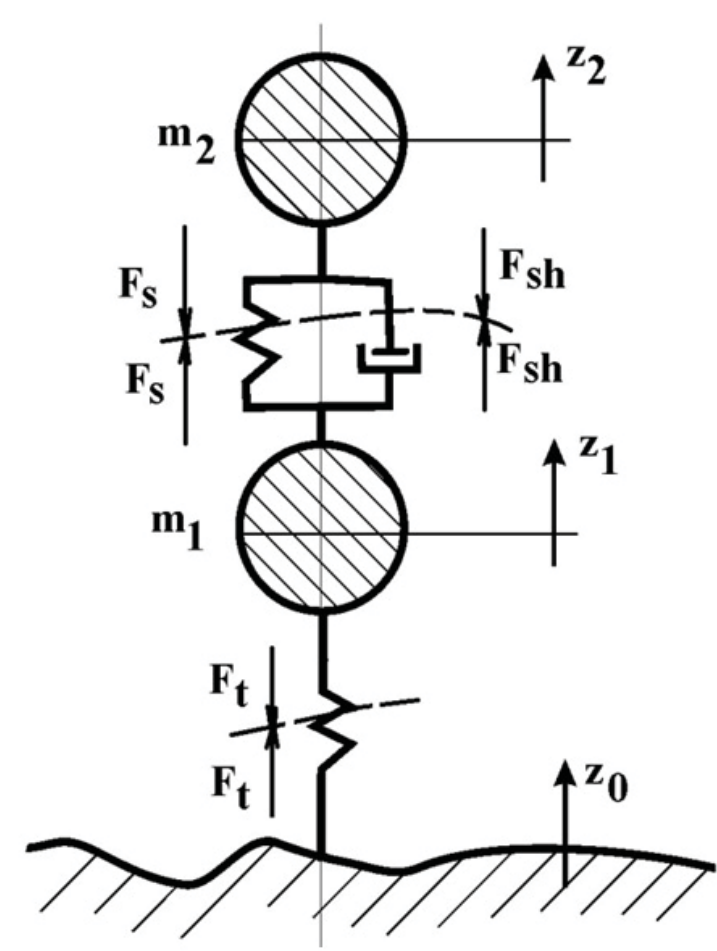

Figure 1: Equivalent vehicle vibration model

- $m_{1}, m_{2}$ - unsprung and sprung mass of a quarter model, respectively (in this case 27.5 and $250 \mathrm{~kg}$ ),

- $F_{s}$ - force in the shock absorber, and

- $F_{t}-$ force in the tire.

The force of the spring can be presented by the third-degree polynomial [7, 9-13, 17-21, 28, 31]:

$$
F_{s}=c_{1} \Delta z+c_{2} \Delta z^{3}
$$


where:

- $c_{1}$ and $c_{2}$ - stiffness parameters, and

- $\Delta z$ - relative deformation of the spring.

The force in shock absorber depends not only on the relative velocity, but also on the relative displacements and relative acceleration [02, 13]. Analyses showed that the model defined in $[02$, 13], which includes transcendental functions of acceleration, can be very difficult to use in the modeling of vehicles with more than one degree of freedom. This follows from the fact that the acceleration of the tangent function included tangent hyperbolicus, so in this case problems occur with decoupling differential equations of motion for models with two or more degrees of freedom. In addition, it was shown that the acceleration is of minor influence on the force then the relative displacement and velocity, and therefore for further analysis model $[02,13]$ is applied, where force is described by the expression:

$$
\begin{aligned}
& F_{s h}=\left\{k_{1}+k_{2,3} \cdot \Delta \dot{z}+k_{4} \cdot \Delta \dot{z}^{2} \operatorname{sign}(\Delta \dot{z})\right\} . \\
& \cdot\left\{k_{5}+k_{6} \cdot \operatorname{th}\left(\frac{\Delta z}{3 \cdot \sigma_{\Delta z}}\right)\right\}
\end{aligned}
$$

where:

- $\Delta z$ i $\Delta \dot{z}$ - relative displacement and velocity, respectively, and

- $k_{1}, k_{2}, k_{4}, k_{5}$ and $k_{6}$ - parameters of shock absorber model.

Radial force in the tire is also nonlinear [07-13, $16,17-20,28,31 /$, and the following expression is used:

$$
F_{t}=c_{3} \Delta+c_{4} \Delta^{2}+c_{5} \Delta^{3}
$$

where:

- $\Delta$ - radial deformation of tire, and

- $c_{3}, c_{4}$ and $c_{5}$ - parameters of tire radial stiffness.

It was estimated to be appropriate for the aim of this study to explore the impact of vehicle speed on the amount of heat energy that is obtained from mechanical work. Therefore, two vehicle speeds were introduced, 10 and $35 \mathrm{~m} / \mathrm{s}$. It is noted that the objective of this study was not to analyze the way of heat dissipation from the shock absorber, because it is not possible without a complicated experimental procedures, but the analysis of the sources of heat in the shock absorber. Analysis was carried out for the case of a vehicle with two passengers, for the motion on a good asphalt road, whose excitation function in time domain is shown in Figure $2 / 7 /$. Specifically, as the excitation a poliharmonial function is used, because the analyses have shown that it is a good approximation for the actual road microprofile [09-12].

Given the observed vibration model of the vehicle, using Newton's law [19, 20, 22, 33], the differential equation of the vehicle vibration motion is dispalyed in the following form:

$$
m_{1} \bar{z}_{1}=F_{s}+F_{s h}-F_{t}
$$

$m z_{2}=-F_{s}-F_{s h}$

where:

- $z_{1}, z_{2}$ - acceleration of unsprung and sprung mass, measured from the equilibrium position, respectively,

- $F_{s}-$ force in spring given by expression (2),

- $F_{s h}$ - force in shock absorber given by expression (3), and

- $F_{t}$ - radial force in tire given by expression (4). Given the highly nonlinear and complex structure of the expressions [02, 03, 04], even in case of such a simple vehicle model, as well as quasistochastic character of excitation functions, it is obvious that the model described in equations $(5,6)$ is complex and cannot be solved in final form.

Analyses showed that the argument of tangent hyperbolicus function in expression (3) - motion divided by triple variation - lies in the field of -1.8 to +1.8 (determined from experimental data [02, 13]). Note that the argument of the observed function mostly belongs to the range -1 to 1 , and the relative error of approximation of the mentioned function by the MacLaurin polynomial of the third degree is about $9 \%[02,13]$, which can be accepted for practical reasons.

During the simulation, parameters of the vehicle "Zastava 1100" were used, obtained from the manufacturer [33], and given in Table 1.

Table 1: The model parameters

\begin{tabular}{|c|c|c|c||c|}
\hline$c_{1}$ & $c_{2}$ & $c_{3}$ & $c_{4}$ & $c_{5}$ \\
\hline 50000 & 10000 & 5000 & 500000 & 500000 \\
\hline \hline$k_{1}$ & $k_{2}$ & $k_{3} / k_{4}$ & $k_{5}$ & $k_{6}$ \\
\hline \hline 20.25 & -9.51 & $0.008 / 0.02$ & -2.091 & 0.0015 \\
\hline
\end{tabular}


It should be noted that the dimensions of the coefficients in Table 1 are in SI unit system.

\section{Thermal load of shock absorber}

Due to the relative motion of the sprung and unsprung masses, mechanical work is being done in shock absorbers, which is equivalent to the amount of heat $Q$ [06, 21-24, 27, 29, 32]. Mechanical work (amount of heat) is defined by the expression [28]:

$$
A=\int_{0}^{s_{r}} F_{s h} d s_{r}=\int_{0}^{T} F_{s h} v_{r} d t
$$

where:

- $F_{s h}$ - force in the shock absorber,

- $s_{r}$-relative displacement of the piston relative to the shock absoprber's body,

- $v_{r}$-relative speed of the piston relative to the shock absoprber's body, and

$$
\text { - } t \text { - time. }
$$

Power required to excite relative motion of the piston relative to the shock absorbers body is given by:

$$
P(t)=F_{s h} v_{r}
$$

As it is well known [06, 21-24, 27, 29, 32], this force is identical to the heat flow (flux) of heat transfer by convection, and its mean value is:

$$
P_{s r}=\frac{1}{T} \int_{n}^{T} P(t) d t
$$

Distribution of most of the amount of heat to the surrounding air is carried out by convection [26, 28, 32]. Formal expression is [06, 21-24, 27, 29, 32]:

$$
\bar{P}=\alpha S \Delta t
$$

where:

$\alpha$ - heat transfer coefficient

$S$ - area that heat is taken from, and

$\Delta t$ - temperature difference between the ambient and external surface of shock absorber.

As already noted, this analysis did not involve the heat dissipation from the shock absorber, because values $\alpha$ and $S$ are not known. It is obvious that a very extensive experimental studies are needed to determine these values, what will certainly be the subject of special attention in the future.

\section{METHOD}

Based on the expressions (1-10), the required parameters of shock absorbers elements are calculated, mechanical work and equivalent heat energy. The aim of this study was to determine the effect of degradation of vibratory parameters, due to their aging in service, on the thermal loading of shock absorber. It was therefore necessary to learn how these changes occur in practice. In the absence of other data, Figure 2 shows the variation of characteristic vibratory parameters of the vehicle with the aging, expressed in kilometers passed [16]. From the Figure 2 it is obvious that the parameters of elasto-damping elements vary during service time. More precisely, their values decrease, and due to the lack of detailed data, it is assumed that the parameter values linearly decrease with the vehicle aging, expressed in kilometers. Data from Figure 2 allow the analysis of the impact of variation of vibration parameters on the variation of dynamic characteristics of the vehicle, i.e. thermal loads of the shock absorber.

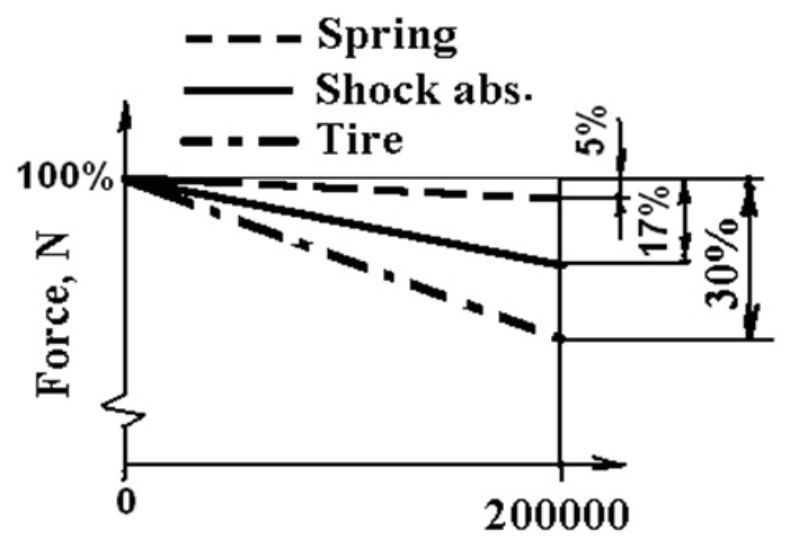

Exploitation, km

Figure 2: Variation of vibration parameters in vehicle service time

For the analysis of the impact of variation of dynamic characteristics of the vehicle caused by the variation of the parameters of elastic-damping elements, due to the aging in exploitation, two groups of parameters were introduced, with corresponding factors that take into account these variations. More precisely, bearing in mind Figure 2, after a straight line approximation, any variation is defined by the equation:

$$
\operatorname{oscpar}(\tau)=\operatorname{oscpar}_{0} \cdot \xi_{i}
$$


where:

- $\operatorname{oscpar}(\tau)$ - value of vibration parameter after mileage of kilometers,

- oscpar ${ }_{0}$ - value of vibration parameter at the beginning of vehicle service, and

- $\quad \xi_{1}$ - factor taking into account degradation of vibration parameters during the vehicle service.

In order to take into account the impact of aging on dynamic characteristics of vehicles in service, based on the data in Figure 2, the corrective parameters are adopted and given in Table 2 . In doing so, it is noted that factor relates to the springs, to the shock absorbers, and to the tires, and two groups of factors: the beginning of the operation are observed: at the beginning of service (group 1 ) and after 200.000 kilometers (group 2).

On the basis of [03-05], statistical error values of signal processing are calculated, and for the illustration only data on errors of spectra calculations are given, because they are calculated using signal averaging. Based on the signal length of 1024 points, time increment of 0.01 , number of averagings 256 , the following values were obtained: "bias" error -0.003 , random error of one signal 0.10 and 0.118 for two crossed signals. Such small values for the errors show that these results enable reliable analysis.

Table 2. Corrective factors of vibration parameters degradation

\begin{tabular}{|c|c|c|c|}
\hline & $\xi_{1}$ & $\xi_{2}$ & $\xi_{3}$ \\
\hline First & 1 & 1 & 1 \\
\hline Second & 0,95 & 0,83 & 0,70 \\
\hline
\end{tabular}

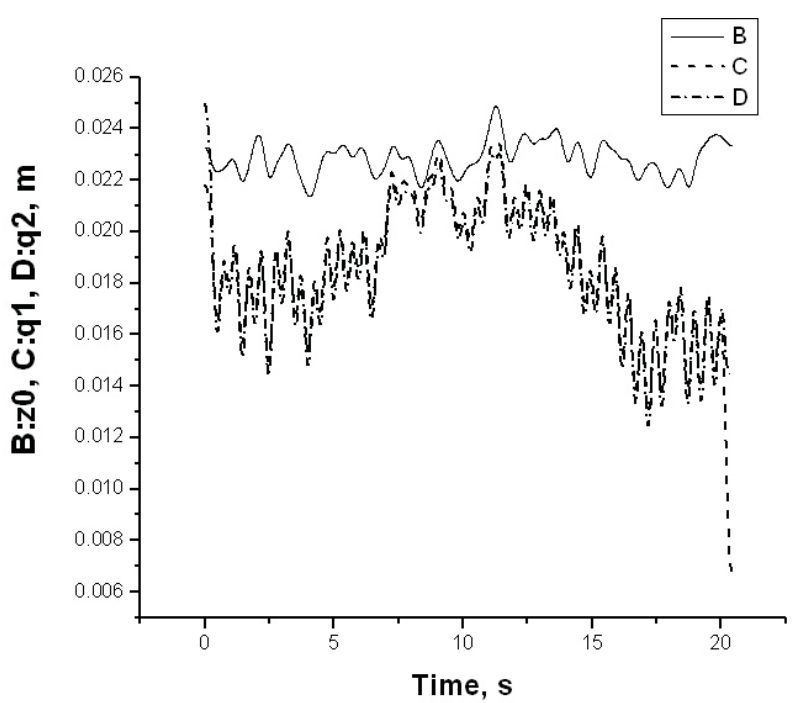

\section{DATA ANALYSIS}

Since a detailed analysis of the impact of variation of vibration parameters on the vehicle vibration system has been reported in [07-13,16$18,28,31$ ], it is considered appropriate to show, in Figure 3, time series of vibration motion of characteristic vehicle masses, while moving over rough road at speed of $10 \mathrm{~m} / \mathrm{s}$, in case of new elements of suspension. Figure 3 shows that random excitation of road microprofile (B), also causes a random function of wheel bounce (c) and supported mass (D).

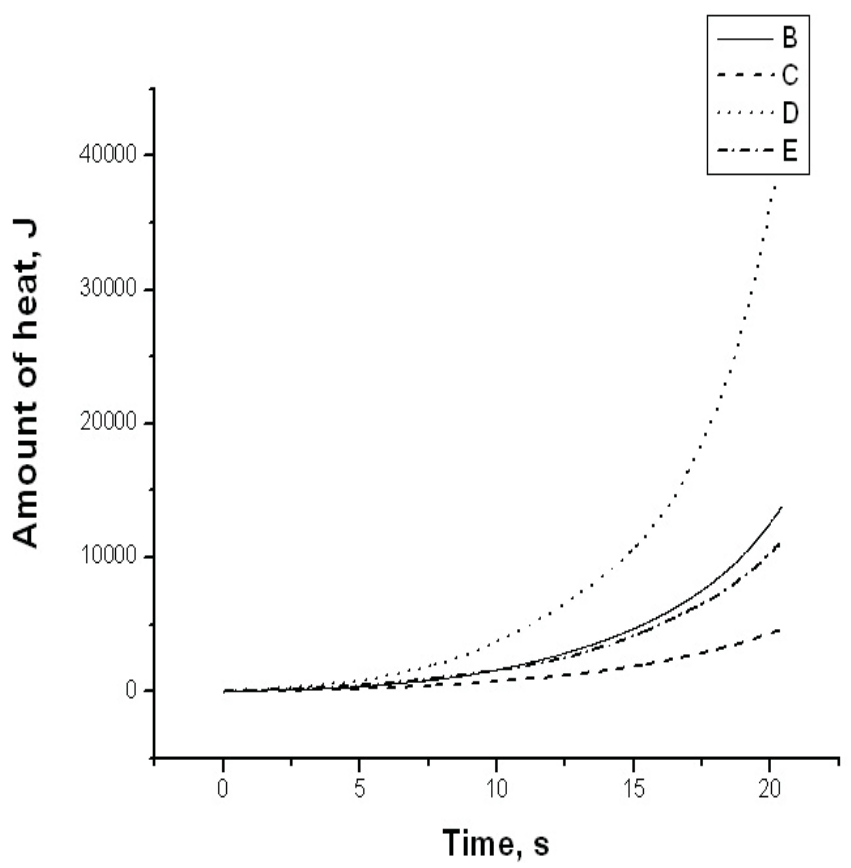

Figure 4: Mechanical work (amount of heat) for a speed of $35 \mathrm{~m} / \mathrm{s}$ (parameters: $B$ - new suspension elements, and $C$ - after service of $200.000 \mathrm{~km}$ ) and a speed of 10 $\mathrm{m} / \mathrm{s}$ (parameters: $D-$ new suspension elements, and $E$ - after service of $200.000 \mathrm{~km}$ )

Mechanical work, calculated according to the formula (7), is converted into heat energy in the shock absorbers, and shown in Figure 4. From the Figure it can be seen that the higher speed of vehicle contributes to the occurrence of a smaller heat load of shock absorbers, in both cases of the applied suspension elements. It is evident that the mechanical work, and consequently, the thermal load of new elements of suspension system, are greater than in those who were in service for $200.000 \mathrm{~km}$, which is logical, given that forces in new shock absorbers are greater.

Figure 3: Excitation function (B), wheel bouncing (c), and sprung mass bouncing (D) at a speed of $10 \mathrm{~m} / \mathrm{s}$ and for the new elements of suspension system 


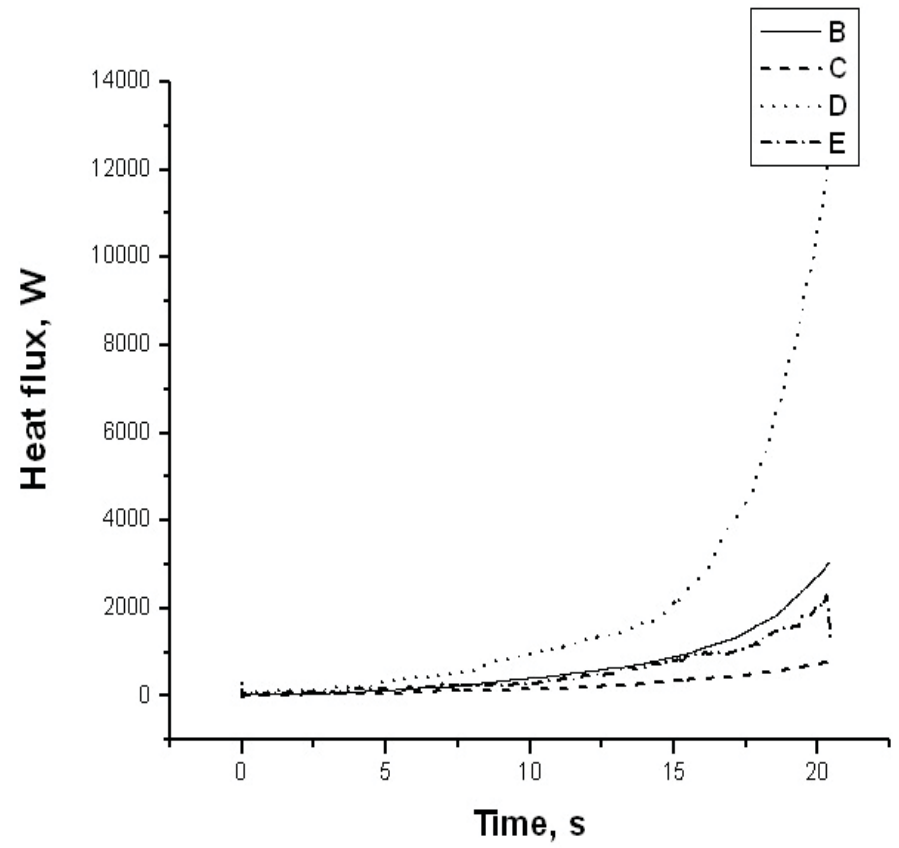

Figure 5: Heat flux for the speed of $35 \mathrm{~m} / \mathrm{s}$ (parameters: $B$ - new suspension elements, and

$C$ - after service of $200.000 \mathrm{~km}$ ) and a speed of 10 $\mathrm{m} / \mathrm{s}$ (parameters: $D-$ new suspension elements, and $E$ - after service of $200.000 \mathrm{~km}$ )

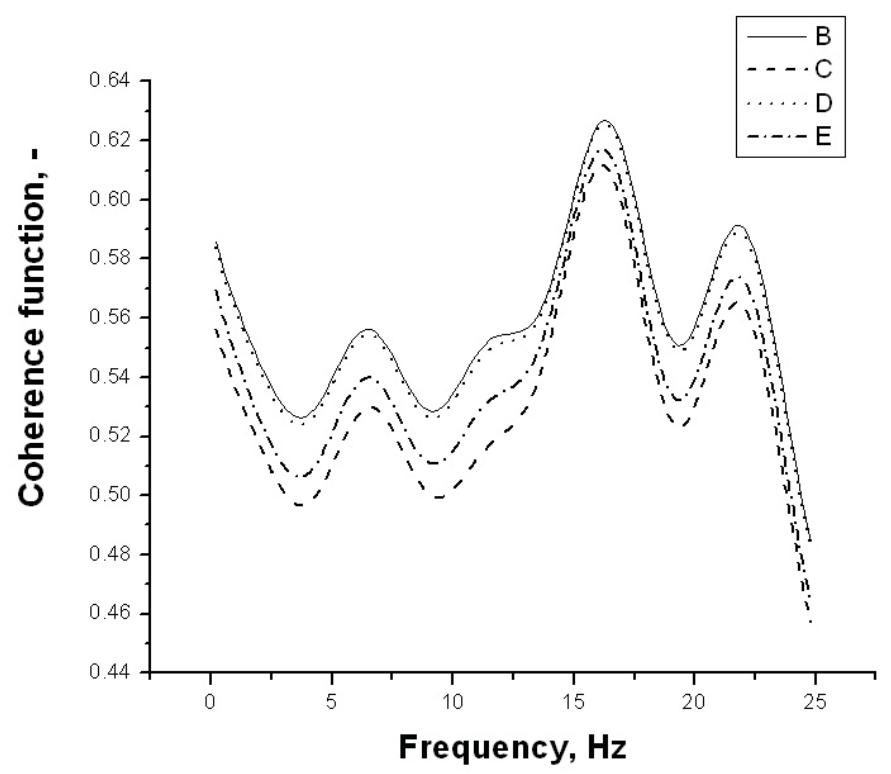

Figure 7: Ordinary coherence function for the speed of $35 \mathrm{~m} / \mathrm{s}$ (parameters: $B$ - new suspension elements, and $C$ - after service of $200.000 \mathrm{~km}$ ) and a speed of 10 $\mathrm{m} / \mathrm{s}$ (parameters: $D-$ new suspension elements, and $E$ - after service of $200.000 \mathrm{~km}$ )

Power that corresponds to the heat flux in shock absorbers is calculated, expression (8), and shown in Figure 4. From the Figure it can be seen that the higher speed of the vehicle contributes to the occurrence of a smaller heat flux in shock

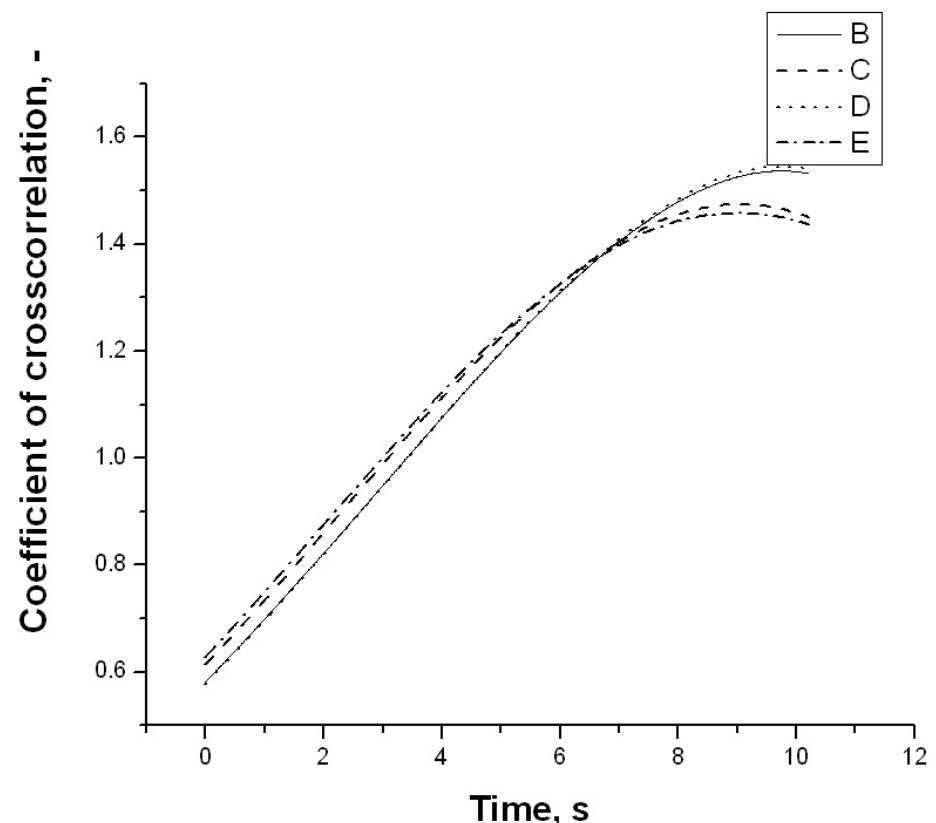

Figure 6: Cross-correlation coefficient for the speed of $35 \mathrm{~m} / \mathrm{s}$ (parameters: $B$ - new suspension elements, and $C$ - after service of $200.000 \mathrm{~km}$ ) and a speed of $10 \mathrm{~m} / \mathrm{s}$ (parameters: $D$ - new suspension elements, and $E$ - after service of $200.000 \mathrm{~km}$ )

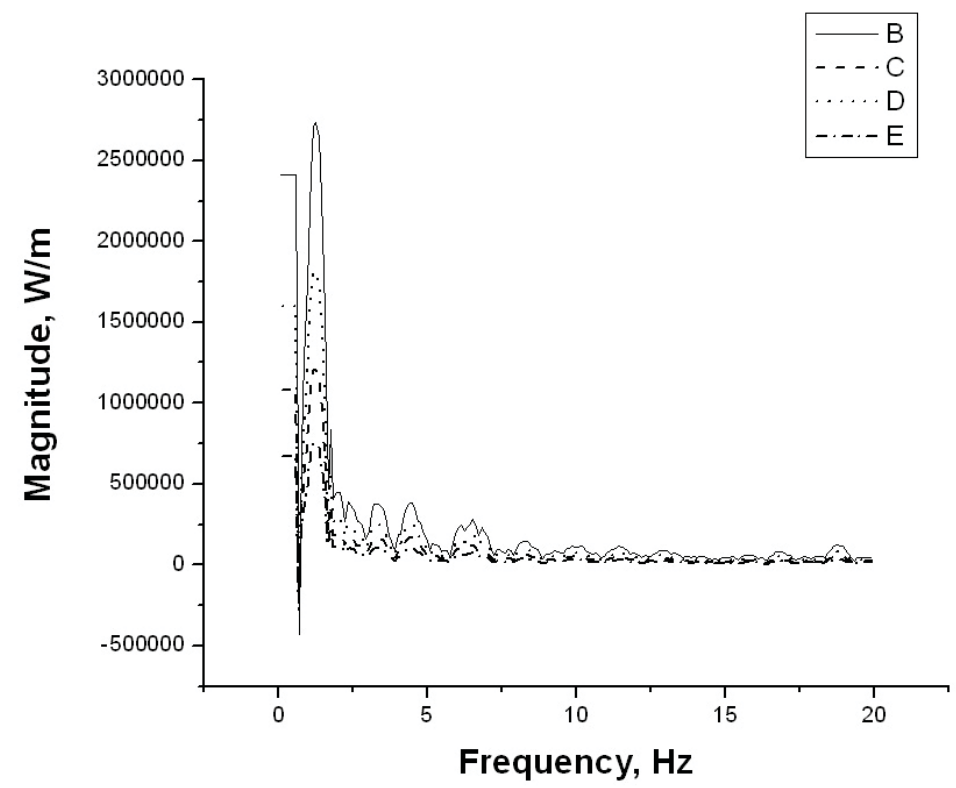

Figure 8. Magnitude of the transfer characteristic for the speed of $35 \mathrm{~m} / \mathrm{s}$ (parameters: $B$ - new suspension elements, and C - after service of $200.000 \mathrm{~km}$ ) and a speed of $10 \mathrm{~m} / \mathrm{s}$ (parameters: $D$ - new suspension elements, and E - after service of $200.000 \mathrm{~km}$ )

absorbers, in both cases of the applied elements of suspension system. It is evident that the heat flux is greater with new elements of suspension system, which is logical, given that forces in new shock absorbers are greater. 
Previously mentioned is illustrated by the data on the mean power, i.e. mean heat flux, expression (9), given in Figure 5, as follows: B: 680,878 , C: 227,549 , D: 2024,819 and $E: 547,802 \mathrm{~W}$. It is obvious that at low vehicle speeds higher mean values of heat flux appear, and given the difficulty in heat dissipation, it is evident that lower vehicle speeds are more critical in terms of cooling of shock absorber.

Calculated cross-correlation coefficient between excitation and heat flux, Figure 6 , has values that are relatively high, which means that in the time domain, between these values, there is a significant coupling /3-5/. It should also be noted here that the influence of speed and the degree of wear of the elements of suspension system can be observed, but it is somewhat less than that concerning heat and flux.

The measured ordinary coherence between road excitation and heat flux, in Figure 7, has values that are relatively high, which means that in the frequency domain, between these values a significant coupling exists /3-5/. In addition, the impact of speed and the degree of wear of the elements of suspension system should be noticed, but it is somewhat less than in case of heat and flux.

The magnitude of transfer characteristic is shown in Figure 8. Obviously, the resonance of the heat flux occurs in an area of around $2.5 \mathrm{~Hz}$, which coincides with the resonances of the sprung mass. It should also be noted that there is an impact of vehicle speed on the heat flux, as a result of the influence of the degree of wear of the elements of suspension system. In addition, in the field of resonance, higher vehicle speeds cause higher heat flux.

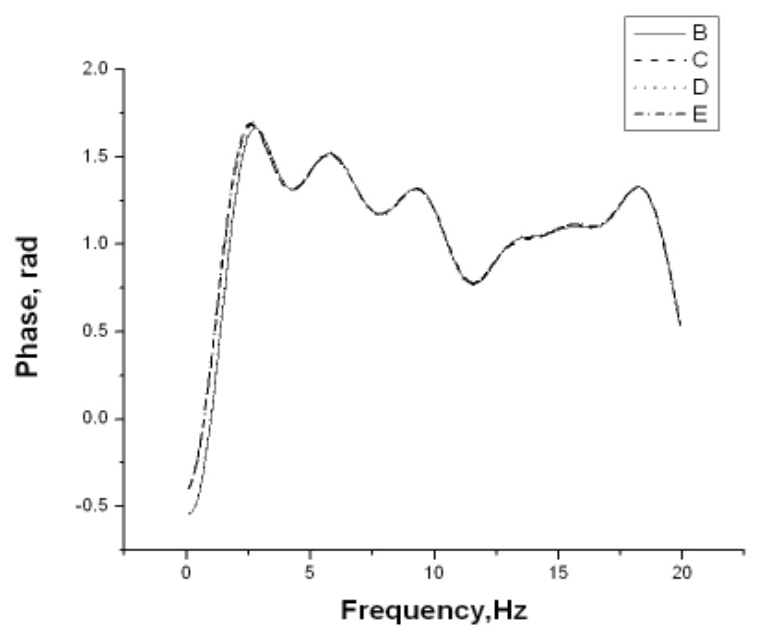

Figure 9: Phase angle for the speed of $35 \mathrm{~m} / \mathrm{s}$ (parameters: $B$ - new suspension elements, and $C$ - after service of $200.000 \mathrm{~km}$ ) and a speed of $10 \mathrm{~m} / \mathrm{s}$ (parameters: $D$ - new suspension elements, and $E$ - after service of $200.000 \mathrm{~km}$ )
Phase angle of the transfer characteristic depends on the frequency. However, in this case the impact of vehicle speed and the degree of wear of the elements of the suspension system on heat flux is of minor importance.

\section{CONCLUSIONS}

Based on the performed research the following can be concluded:

- thermal load of shock absorbers can be investigated based on the results of dynamic simulation,

- vehicle speed affects the thermal loads of shock absorbers. Thermal loads are higher at lower speeds,

- variation of vibration parameters during the service time influences the thermal load of shock absorber. Thermal loads are also higher with new shock absorbers, and

- in the period to come, the experimental research should be carried out to allow the analysis of the heat dissipation (cooling) of shock absorbers.

\section{REFERENCES}

1) Atkins, P. (2010), The Laws of Thermodynamics (A Very Short Introduction), Oxford.

2) Belingardi, G., Demić, M. (2009), A possible model for shock absorber by using the „Black box" method, Journal of Applied Engineering Science, VII/4, pp. 45-53.

3) Bendat, J. and Piersol, A., (1980), Engineering applications of correlation and spectral analysis, John Wiley and Sons, New York.

4) Bendat, J. and Piersol, A., (2000), Random data analysis and measurement, John Wiley and Sons, London.

5) Bendat, J., Nonlinear Systems - Techniques and Applications, (1998), John Wiley and Sons, London.

6) Bojić, M., (2011), Thermodynamics (in Serbian), Mechanical Engineering Faculty, Kragujevac.

7) Demić, M. (1997), The optimization of vehicle vibration systems (in Serbian), Mechanical Engineering Faculty, Kragujevac.

8) Demić, M., (2004), Design of passenger cars (in Serbian), Mechanical Engineering Faculty in Kragujevac. 
9) Demic, M. (1999), The definition of the tires limit of admissible nonuniformity by using the vehicle vibratory model. Vehicle System Dynamics 31 (3), pp. 183-211

10) Demić, M., (1994), Optimization of Vehicles Elasto-Damping Element Characteristics from the Aspect of Ride Comfort, Vehicle System Dynamics, Vol. 23, pp.351-377.

11) Demić, M. (1996), Optimization of Characteristics of Elasto-Damping Elements from the Aspect of Oscillatory Comfort and Vehicle Handling, Int. J. of Vehicle Design, Vol. 17, No 1.

12) Demić, M., Diligenski, Đ., Demić, I., Demić, M. (2006), A method of vehicle active suspension design, Forschung Im Ingenieurwessen, 5, 70: DOI 10.1007/s10010-06-0025, pp 145-158.

13) Demić, M., Belingardi, G. (2010), A Contribution to shock absorber modelling and Analysis of their Influence on Vehicle ride Charakteristics, Journal of Middle European Construction and Design of Cars (MECCA), 01, pp 6-17.

14) Demić, M., (2003) Analsigdem Software for signal analysis, www.ptt.yu/korisnici/i/m/imizm034/index.swf.

15) Demić, M. (2003), Demparcoh Software, www.ptt.yu/korisnici/i/m/imizm034/index.swf

16) Demić, M., Diligenski, Đ. (2012): A Contribution to Research of Degradation of Characteristics of Vibration Parameters on Vibration Aspect of Vehicle Comfort, Journal of Applied Engineering Science, Vol. 10, No 4., pp.185-190.

17) Genta A. (2003), Motor Vehicle Dynamics. Politecniko di Torino.

18) Gillespie T. (1992), Fundamentals of Vehicle Dynamics. SAE, Warrendale.

19) Magneti Marelli, (2012), Informations.

20) Miliken WF, Miliken D.L., (1995), Race Car Vehicle Dynamics. SAE, Warrendale, 1995.
21) llić, G., Radojković, N., Stojanović, I., (1996), Thermodynamics II - The basics of heat transfer (in Serbian), Mechanical Engineering Faculty, Niš.

22) Malić D., (1972), Thermodynamics and thermotechnics (in Serbian), IP "Gradjevinska knjiga“, Belgrade.

23) Milinčić D., Vasiljević B., Djordjević R., (1984), Problems with heat transfer (in Serbian), IP Gradjevinska knjiga“, Belgrade.

24) Marić, M., (2002), Thermal Science - thermodynamics, heat transfer, combustion (in Serbian). University of Novi Sad, Faculty of Technical Sciences.

25) Milinčić D., Voronjec D., (1991), Thermodynamics (in Serbian), Mechanical Engineering Faculty, Belgrade 1991.

26) Mohd Sh., Mohd. S., Erlifi H., Nor, M. M., (2008), Experimental heat transfer study on the shock absorber operation", International Conference on Science \& Technology: Applications in Industry \& Education,

27) Moran, M.J. et al., (2010), Fundamentals of Engineering Thermodynamics, Wiley.

28) Mitschke, M., (1997), Kraftfahrzeugkonstruktion, Teil D., TU Braunschweig, Forlesung.

29) Fermi, E., (2011), Thermodynamics, Dover Books on Physics.

30) Riesenburg, O., (1970), „Beitrag zur Klärung der Vorgänge in einem hydraulischen Schwingungsdämpfer", Dissertation TU Braunschweig.

31) Rajamani, R., (2005), Vehicle Dynamics and Control, University of Minesota.

32) Šelmić, R., (1986), Technical thermodynamics (in Serbian), Naučna knjiga, Belgrade.

33) Zastava informations (1977-2010) (in Serbian).

Paper sent to revision: 22.01.2013.

Paper ready for publication: 06.03.2013. 